\title{
Bilgi Yönetiminin İşletmelere Yenilik ve Rekabet Üstünlüğü Sağlaması
}

\begin{abstract}
Ali DURDU, Ankara Sosyal Bilimler Üniversitesi, Yönetim Bilişim Sistemleri ABD. Dr. ÖgrretimÜyesi, ali.durdu@asbu.edu.tr, (D) 0000-0002-5347-4491

Emine İPEK, Ankara Sosyal Bilimler Üniversitesi, Denetim ve Risk Yönetimi, Yüksek Lisans Öğrencisi, emine.ipek@student.asbu.edu.tr, (D) 0000-0001-9561-4694

$\ddot{O Z Z}$

Günümüzde bilgi, hayatımızın en önemli faktörü olarak nitelendirilmektedir. Bilgiyi yönetebilmek için teknolojik gelişmelere ayak uydurabilmek gereklidir. Bilgi yönetimi, işletmelerde rekabet avantajı sağlamakta ve işletmelerin pazar değerini artırmaktadır. Ortaya çıkan firsatlar rakiplerden önce görebilmek ve bunun sonucunda elde edilen üstünlüğ̈̈ uzun vadede sürdürebilmek bilgi yönetiminin belirleyici rolleri olarak görülmektedir. Çalışmada, bilgi, bilgi yönetimi kavramları incelenmiş, bilgi yönetiminin amaçlarn ve işletme için önemine değinilmiş, bilgi yönetiminin işletmeye sağladığı yenilik ve rekabet üstünlüğü ortaya koyulmuştur.
\end{abstract}

Anahtar : Bilgi, Yenilik, Rekabetçilik, Yönetim, Bilgi Yönetimi

Kelimeler

\section{Information Management Provides Innovation And Competitiveness To Businesses}

\begin{abstract}
Today, knowledge is considered as the most important factor of our life. In order to manage information, it is necessary to keep up with technological developments. Information management provides competitive advantage in enterprises and increases the market value of businesses. Being able to see the emerging opportunities before competitors and maintaining the resulting superiority in the long term is seen as the determining roles of information management. The importance of the information management and the innovation and competitive advantage of the business were revealed.
\end{abstract} Keywords : $\quad \begin{aligned} & \text { Knowledge, Innovation, Competitiveness, Management, Knowledge } \\ & \text { Management }\end{aligned}$

\section{GİRIŞ}

Günümüzde rekabet koşullarının artmasıyla birlikte bilgi, işletmeler için en değerli üretim faktörü olmuştur. Tabiki işletmelerin bu rekabet ortamına ayak uydurabilmeleri için de bilgiyi yönetebilmeleri gereklidir. 
Bilgi yönetimi, "işletmelerin rekabet avantajı sağlayabilmeleri için bilgiyi sistematik şekilde oluşturarak, değişen ortama ayak uydurarak yenilenmesi, depolanması, aktarılması ve kullanılması" şeklinde tanımlanabilir. İşletmeler bir çok konuda yatırım yapmaktadır. İşletmeler çalışanlarının sahip olduğu bilginin öneminin de farkında olmalıdır. Bundan dolayı da işletmeler, insan sermayesine odaklanarak çalışan bilgi ve becerisini geliştirmeye odaklanmalıdırlar. Bilgiyi yönetebilmek adına işletmeler teknolojik yatırımlara önem vermektedir ama bilgi yönetimi sadece teknolojik yatırımlardan oluşmamaktadır. Aslında teknoloji bilgi yönetimi sürecinde bir amaç değil araç olarak kullanılmalıdır. İşletmeler için günümüzde artan rekabet koşullarıyla birlikte bilginin sistematik olarak nasıl yönetilebileceği ve nasıl bir rekabet avantajı sağlayabileceği oldukça önemli bir konudur (Uzun \& Durna, 2008)

Bu çalışmada, bilgi, bilgi yönetimi kavramları incelenmiş, bilgi yönetiminin amaçları ve işletme için önemine değinilmiş, bilgi yönetiminin işletmeye sağladı̆̆ 1 yenilik ve rekabet üstünlüğü ortaya koyulmuştur. Çalışmanın amacı bilgi yönetiminin işletmeler için hem rekabet hem yenilik avantajı sağladığının farkındalığının yaratılmasıdır. Çalışmanın 2. bölümünde bilgi kavramı ve bilginin önemi, 3. bölümünde bilginin bilişim teknolojileri ile ilişkisi, 4. bölümünde bilgi yönetimi ve süreci açıklanmaya çalışılmıştır. 5. bölümde bilgi yönetiminin yararları, 6. bölümde bilgi yönetiminin rekabetle ilişkisi 7. bölümde bilgi yönetiminin yenilikle ilişkisinden bahsedilmiştir. Sonuç kısmında ise bilgi yönetiminin hem rekabet hem de yenilik yönünden avantajları ele alınmıştır.

\section{Bilgi Kavramı ve Bilginin Önemi}

\subsection{Bilgi Kavramı}

Bilgi temel olarak örgütsel faaliyetlerin en temel girdisi şeklinde tanımlanabilir. Başka bir deyişle veri olarak adlandırdığımız gerçeklerin, olayların toplanması ve toplanan verilerin çeşitli yöntemler kullanılarak incelenip analiz edilmesiyle ortaya çıkan sonuçlar biçiminde tanımlamıştır (Certo, 1989). Bilgi kavramını daha iyi anlayabilmek için kavramla ilişkili olan veri ve enformasyon kavramlarının da iyi analiz edilmesi gereklidir.

Veri ham, işlenmemiş enformasyon parçacığına verilen addır. Veri, yorumlanmamış ve özümlenmemiş gözlemler, işlenmemiş gerçekler şeklinde tanımlanabilir (Barutçugil, 2002).

Örgütlerin hepsinin veriye ihtiyacı olduğu bilinmektedir bu yüzden örgütün enformasyon ve bilgi üretebilmesi için gerekli veri sayısının ve türünün iyi bilinmesi gereklidir (Awad \& Ghaziri, 2010).

Enformasyonu verilerin düzenlenmiş şekli olarak tanımlayabiliriz. Düzenlemeyi başkası yapar ve yapılan düzenleme sadece ilgili kişi için anlam ifade etmektedir (Barutçugil, 2002). 
Bilginin oluşmasında da kaybolmamasında da veri ve enformasyon, unutulmaması gerekli önemli iki unsurdur. Enformasyon ve veri birbirinden ayrı düşünülemez. Yani veri olmadan enformasyon, enformasyon olmadan bilgiye ulaşmak oldukça güçtür (Abdullah et al., 2005).

\subsection{Bilginin Önemi}

Bilgi kavramı tarih boyunca toplumları ilgilendirdiği gibi günümüzde de bütün toplumları ilgilendirmektedir. İçinde bulunduğumuz bilgi çağında herkesin bilgi toplumuna ulaşma yolları araması ve bilgi kavramının herkesi ilgilendirmesi çok doğal bir sonuç olarak karşımıza çıkmaktadır. Bilgi iç yaşamımızın mükemmelleşmesini, varlığımızın değişmesini sağlar, insan olarak sosyalleşmemize yardım eder ve bu sosyal süreci alabildiğine hızlandırır.

\section{Bilginin Bilişim Teknolojileri ile İlişkisi}

Gelişen dünyada bilişim teknolojisine ihtiyaç duymamak mümkün değildir. Bilişim teknolojilerine bu kadar ihtiyaç duymasının temel nedeni olarak, içinde bulunulan sistemlerin giderek genişlemesi, daha karmaşık hale gelmesi ve çevreye ayak uydurma gösterilebilir. Örgütler için bilişim teknolojileri başarılı ya da başarısız olma durumunu belirleyen en önemli güç olarak ifade edilmektedir (Öğüt, 2001).

Bilişim teknolojilerinin örgütler için stratejik bir kaynak haline gelmesiyle birlikte işletmeler artan rekabet koşullarına uyum sağlamak için bu teknolojilere yönelerek yatırımlarını bu yönde yapmaya başlamışlardır (Earl, 1991).

\section{Bilgi Yönetimi ve Süreci}

Temel olarak bilgi yönetimi, rekabet avantajı sağlamak için bilgiyi oluşturarak bulma, elde etme ve kullanılması için uygulanan stratejik süreçler bütünü şeklinde tanımlanabilir. Başka bir deyişle, bilgi yönetimi; örgütlerin hedeflerine ulaşabilmesi için bilgiyi nasıl yaratabilecekleri, nasıl elde edip kullanabilecekleri ve nasıl yönetilebileceğini anlatan strateik bir süreç olarak tanımlanabilir (Özgener, 2002).

Bilgi yönetimi süreciyle ilgili pek çok görüş ileri sürülmüştür. (Davenport \& Prusak, 2001), bilgiyi üretmek, bilgiyi kodlamak, koordinasyon sağlamak ve son olarak bilginin transferini önermiştir (Güçlü \& Sotirofski, 2006).

(Malhotra, 2003) ise, bu yönetim sürecinini 6 basamakta değerlendirmiştir. Bunlar, bilginin farkında olmak, bilginin amaçlarını belirlemek, bilgiyi uygulamak, yaymak, geliştirmek ve saklamaktır (Güçlü \& Sotirofski, 2006). 


\subsection{Bilgi Yönetiminin Tanımı, Amacı ve Önemi}

Amerikan Kalite ve Üretim Merkezi tarafından bilgi yönetimi, bilginin ortaya çıkarak doğru insana doğru zamanda değer yaratmasını sağlamak için sistematik yaklaşım olarak tanımlanmaktadır (Buckman, 2004).

Başka bir ifadeyle bilgi yönetimi sürekli gelişen ve artan bilgi kapasitesini güncel tutan, elde edilen bilgileri ulaşılabilir hale getiren ve gerekli bilginin örgütteki diğer kişilerle paylaşılmasını öngören bir disiplin olarak ifade edilebilir (Harrison \& Kessels, 2003).

Bilgi yönetiminin amacl; üretimi, karar vermeyi, rekabeti, sürekliliği, kaynak aktarımını, gelişimi hızlandırmak ve isabetlendirmek için kurum içindeki açık bilginin dolaşımını sağlayarak, kapalı bilgiyi de ortaya çıkararak kurum için verimli olacak en doğru kişilere iletmektir (Çapar, 2003).

Nonaka bilgi yönetiminin önemini şöyle ifade eder: “Belirsizlik her zaman hayatımızda mevcuttur ve ekonomide rekabet üstünlüğü sağlamanın tek güvenilir yolu bilgidir. Piyasalar geliştikçe ve değiştikçe rakipler ve teknolojiler çoğalacak bunun sonucunda bu teknolojilere uyum sağlayabilen, bilgiyi kullanabilen ve yönetebilen firmalar başarılı olarak nitelendirilecektir" (Nonaka, 1999).

\subsection{Bilginin Üretilmesi}

Bilgi var olan bilginin elde edilmesi ve yeni bir bilgi yaratılması gibi 2 şekilde incelenebilir.

\subsubsection{Bilginin Elde Edilmesi}

Şirketler taklit etme, kiralama ve satın alma yoluyla bilgi elde edebilirler. Bilgiyi taklit etme; Bir şirketin başka bir şirkette başarılı olarak uyguladığını gördüğü bilgiyi veya yeni üretilen bir bilgiyi kendisine örnek alarak uygulayıp kullanmasıdır. Bilginin kiralanması demek aslında bilginin kaynağını kiralamak demektir. Bu konuya verilebilecek en iyi örnek belirli bir konu ya da proje için danışmalık hizmeti almaktır. Bilginin satın alınması ise, Bilginin sahibi olan kurum kuruluşu satın alarak ya da kurum kuruluş içinde çalışan insanları işe alarak gerçekleştirilebilir. 


\subsubsection{Yeni Bilgi Üretilmesi}

Genel olarak bilginin üretilmesi birçok şekilde gerçekleşse de müşteriyle birlikte bilgi üretilmesi, stratejik ortaklarla üretim, risk sermayesi yoluyla üretim, ve bilgi şebekeleri en bilinenleri arasında sayılabilir.

\subsection{Bilginin Sınıflandırılması ve Depolanması-Saklanması}

\subsubsection{Bilginin Sınıflandırılması}

Bilgiyi sınıflandırmanın temel amacı bilgiyi herkes için ulaşılabilir ve kolay bir hale getirerek uygulanmasını sağlamaktır (Davenport \& Prusak, 2001).

Bilginin sınıflandırılmasıyla birlikte bilgi yönetiminin ana amaçlarından olan bilginin doğru kişiye ulaşıp doğru biçimde kullanılması da kolaylıkla gerçekleşecektir.

\subsubsection{Bilginin Depolanmas1}

Bilgi hizmetlerde, ürünlerde, kişilerde ve süreçlerde depolanabileceği gibi işletmelerin genelinde de depolanabilir.

\subsection{Bilginin Paylaşılması-Yayılması}

Ulaşılamayan ve şirket içinde yayılmayan bilgi tam anlamıyla bilgi birikimi ve sermaye olarak değerlendirilemez. Bundan dolayı şeffaf ve açık olmak bilgi yönetimi açısından oldukça önemlidir (Akdeniz, 2002).

Aslında bilginin paylaşımı insanlara ulaşmak istedikleri amaçlara rahatça ulaşabilmeyi ve işlerini kolaylaştırmayı sağlamaktadır. Çalışma ortamında da itibar kazandırmaktadır. Yöneticiler bilginin paylaşılmasını yaygınlaştırmak için çalışanları teşvik ve ödüllendirme sistemi kurabilirler.

\subsection{Bilginin Kullanılması}

Şirketlerin yaşamını devam ettirebilmesi için bilgiyi kullanmaları ve uygulamaları oldukça önemlidir. Şirketlerin rekabet ortamında güçlü kalabilmesi adına tek başına bilginin korunması ve saklanması değil aynı zamanda bilginin etkin bir biçimde kullanılması ve uygulanması gereklidir (Kalkan et al., 2006).

Bilginin kullanılabilmesi için öncelikle bilginin öğrenilmesi gereklidir. Öğrenen organizyon olabilmek günümüzde oldukça önemlidir. Organizasyon düzeyinde öğrenme; "kişisel ve grup olarak ulaşılan ortak değer ve anlayışların organizasyonun tümü için geçerli prosedür, yöntem, sistem, davranış kalıpları ve organizasyondaki herkesin kolayca ulaşabileceği toplu bir veritabanına dönüştürülmesi olarak ifade edilebilir" (Koçel, 2003). 
Bilginin kullanılması bilgi yönetimi süreçleri bakımından stratejik olarak en önemlisi olarak değerlendirilebilir. Bilgi kullanıldıkça bilginin sahip olduğu potansiyel değer gerçek değere dönüşür. Günümüzde yapılan araştırmalar bilgiyi 3 şekilde kullanabileceğimizi ortaya koymaktadır. Birincisi, bilginin doğrudan kullanılmasıdır. Bilgiyi doğrudan problem çözümünde ya da belirli bir amacın yönetilmesinde kullanmak bu kapsamda örnek olabilir. İkinci olarak, bilginin dolaylı yoldan kullanılmasıdır. Yani başka bir bilgiye ulaşmak amacıyla genel bir fikre sahip olmak amacıyla ya da bilgi birikimi elde etmek amacıyla kullanılmasıdır. Bilginin dolaylı yoldan kullanılması ilk etapta herhangi bir problem çözümüne veya karar alma süreçlerine katkı yapmadığı düşünülse de uzun vadede kararların sağlıklı alınması ve karşılaşılan problemlerin doğru şekilde çözümüne dolaylı olarak katkı yapmaktadır. Üçüncü olarak ise bilginin sembolik olarak kullanılması yer almaktadır. Bilginin amacı dişında kullanılması anlamına gelmektedir. Örneğin, bilerek bir bilginin saklanması, piyasa araştırması sonuçlarının gerçek dışı ifade edilmesi, veya sadece kişilerin ve kuruluşların çıkarlarına uygun olarak ifade edilmesidir (Zaim, 2005).

\subsection{Bilginin Değerlendirilmesi ve Ölçülmesi}

Bilgi kullanımında verimliliğin de dikkate alındığı aşama bilginin değerlendirilmesi olarak nitelendirilir (Kalkan et al., 2006). Bilginin kurumlara ne kadar katkı yaptığını hesaplayabilirsek aslında bilgiyi ölçmüş ve değerlendirmiş oluruz. Von Krogh bilginin değerinin üç şekilde ölçüldüğünü söyler (Zaim, 2005). Birincisi stratejik değerlendirmedir. Stratejik değerlendirme, Bilgiyi artan rekabet ortamında rakiplere karşı avantaj sağlaması yönünden ve organizasyonu geliştirmesi yönünden kullanmaktır. İkinci olarak paydaşlar açısından değerlendirmedir. Yani bilgiyi paydaşların talepleri doğrultusunda kullanmaktır. Üçüncüsü değerlendirme ise hissi değerlendirmedir. Bu da bilginin ne derece kaliteli olduğunu çalışanların davranışlarına ne derece etki ettiğini ve estetik değerini ölçmek olarak nitelendirilebilir. Von Krogh'a göre bilgi kavram olarak değerlendirilmenin yanı sıra hizmet, ürün ve süreç itibariyle de değerlendirilebilir.

\section{Bilgi Yönetiminin Yararları}

Organizasyonlar günümüzde teknolojiye ayak uydurmak, gelişen dünyaya uyum sağlamak ve tüm bu konularda rekabet avantajı sağlamak için bilgi yönetimine oldukça önem vermektedirler. Bu önemle birlikte de bilgiyi kullanırken yararlarını da anlamlı bir biçimde ortaya koymaları gerekmektedir (Sarıhan, 1998).

(Canbazoğlu, 2000) bilgi yönetiminin yararlarını şu şekilde sıralamıştır;

1.Bilgi kaybını önlemek: Tüm örgütün sahip olabileceği bir hafıza oluşturararak, çalışanlar işten ayrılsa da emekli olsa da çeşitli değişimler olsa da oluşabilecek bilgi kayıplarını önler ve işletmelerin bilgi uzmanlığının korunmasını sağlar. 
2.Daha etkin kararlar alabilmek: Etkin kararlar alabilmek adına gerekli olan bilginin kalitesini ve tipini belirleyerek bilgiye ulaşımı olanaklı kılar. Buda kararların daha kaliteli, verimli ve hızlı olarak işletme içinde yayılmasını sağlar.

3.Uyarlanabilirlik ve esneklik: Çalışanların işlerini yaparken daha serbest olmalarına, daha az gözetim altında çalışabilmelerine, yenilikçi çözüm yolları araştırabilip önerebilmelerine, ve işlerine daha hakim olabilmelerine olanak sağlar. Buda işletmede bilginin daha geniş ağlara yayılmasını sağlar.

4.Rekabet avantajı sağlamak: İşletmelerin günümüz artan rekabet ortamlarına uyum sağlayabilmeleri bu rekabet ortamından avantajlı çıkabilmeleri ve fırsatları değerlendirebilmelerine yardımcı olur.

5.Varlık geliştirme sağlamak: Bilgi sermayesine yasal korumanın eklenebilmesi için işletme varlığını ve yeteneklerini geliştirir. Patentler, lisanslar, tescilli markalar, ticari sırlar ve kopya hakları doğru zamanda uygulanmazsa daha düşük düzeyde yasal koruma sağlayacağından doğrudan işletmenin pazar payını ve değerini de etkileyecektir.

6.Ürün iyileştirme sağlamak: İşletmelerin ürünlerine ve hizmetlerine bilgiyi ekleyebilmelerine imkan sağlar. Böylece müşterinin algıladığı ürünün değeri bilginin kalitesine ve derecesine bağlı olarak doğrudan etkilenerek artar.

7.Müsteri yönetimi sağlamak: İşletmelerin hem verdiği hizmetlere hem de müşterilere odaklanmasına olanak sağlar. İşletmeler artan müşteri bilgileri sayesinde müşterilerden gelen istek, talep ve şikayetlere daha kolay ve verimli cevaplar verebilirler. Aynı zamanda çalışanların erişebileceği ortak bir müşteri veri tabanı da oluşturularak benzer sorunlarla daha kolay başedilebilir.

8.İnsan sermayesine yatırımın değeri arttırmak: Bilgi yönetildikçe elde edilen bilgiler daha çok paylaşılacak, yayılacak ve iletilmesi kolaylaşacaktır bu da çalışanların işe alınma ve eğitim sürecinde yapılan yatırımların değerini arttıracaktır.

\section{Rekabetçilik ve Bilgi Yönetimi}

Günümüzde rekabetçi işletmeler ortaya çıkaran ve uzun vadede bu rekabetçiliği sürdüren en önemli faktör, devamlı gelişmekte olan "temel yetkinlikler" olarak görülmektedir. Temel yetkinlikler işletmenin becerilerinin arka planda destekleyicisi ve başarılı stratejik uygulamaların ana taşlarıdır (Barca, 2002). Bilgi ve bilgi yönetimi bu temek yetkinliklerin özünü oluşturur.

En basit tanımıyla rekabetçilik rakiplere karşı üstünlük sağlama amacı ile daha verimli müşteri değeri yaratıp piyasada avantaj kazanmak olarak ifade edilmektedir. Birçok yolla rekabetçi olunulabilir. Rakiplerinden önce kendine müşteri değeri yaratarak yeni pazar fırsatları oluşturmak, rakiplerine karşı fiyat, ürün kalitesi, tedarik, ulaştırma avantajı elde etmek, 
sürekli değişen müşteri ihtiyaç ve isteklerine zamanında yanıt verebilmek işletmeyi rekabetçi bir işletme yapan birkaç yöntem olarak söylenebilir (Şimşek \& Akın, 2003)

Aslında tüm bu belirtilen yöntemler arasında en önemlisi bilgi yönetimidir. Günümüzde rekabet şartları çok hızlı değiştiği için işletmeler bilgi yönetimini geliştirmeye ve kullanmaya odaklanmalıdırlar. İşletmelerin rekabetle başa çıkabilmeleri için bilgi yönetimini geliştirmeye teşvik etmeleri ve çalışanları için profesyonel eğitim olanakları sunarak tüm bunları işletmenin kalıcı bir unsuru haline getirmeleri doğru bir karar olacaktır (Carneiro, 2000).

Tüm dünyada olduğu gibi ülkemizde de bilgi ve rekabet üstünlüğü kavramının iki önemli güç olduğu anlaşıldıkça bilgi yönetimi konusuna da verilen önem artacaktır.

\section{Yenilik ve Bilgi Yönetimi}

Yenilik ifadesi $\mathrm{TDK}^{\prime}$ da "yeni olma durumu veya yeni olan bişeyin özelliği" olarak tanımlanmakta iken çoğu kaynaklarda da İngilizce karşılığı olan inovasyon kavramıyla ifade edilmektedir. Bu kavram süreç olarak yenileme ve yenilenme olarak ifade edilirken aynı zamanda bir sonucu yani yeniliğide ifade eder.

Günümüzde üretimin temeli yenilikçilik yani inovasyon kavramıyla oluşmaktadır. Yapılan teknolojik ve bilimsel araştırmaların sonucu olarak ortaya çıkan bulguları toplumun ve ekonominin yararına çevirmek yenilikçilik olarak tanımlanabilir. Yani yapılan teknolojik ve bilimsel araştırmalar sonucu ortaya çıan bulguları, pazarlanabilecek yeni ürünler, sistemler, yeni hizmetlere ve yeni üretim yöntemlerine dönüştürebilmek; ya da aynı bulguları, mevcut sistemleri, ürünleri ve toplumsal hizmetleri teknolojik açıdan iyileştirmek demektir (Sümer, 2003).

İşletmelerin rekabet güçlerini elde tutmaları birçok unsuru ellerinde bulundurmalarına bağlıdır. Rekabette önemli olan bu unsurlar kalite, fiyat, hız, ürün olabilir. Bunların yanında yenilikçi süreçlerle birlikte pazara yeni ürünler sunabilmek de rekabet için önemli bir unsurdur. İşletmeler rekabet ortamında ayakta kalabilmek için ürünlerinde sürekli yenilikçi olmalıdır. Dolayısıyla rekabetçi işletme olabilmek için yenilik ve yenilikçilik kavramları oldukça önemlidir.

Klasik iktisatta üretimin dört temel girdisi olarak tanımlanan emek,sermaye,doğal kaynaklar ve girişimcinin yanı sıra günümüzde bunlara ek olarak artık "bilgi” de bu girdilerin arasında yer almaktadır.Bundan dolayı işletmeler artan rekabet ortamında ayakta kalabilmenin temelini bilginin oluşturduğunun bilincindediler.Bu bilginin üstünlüğünün sağlanması da yenilikçiliğin sürdürülebilmesi ile olmaktadır.Bundan yola çıkarak yenilikçiliği "yeni bilgi üretebilmek için bilginin kullanılması olarak" tanımlayabiliriz (Sümer, 2003). 
Teknolojik yenilikleri sürdürerek rekabet gücünün korunabilmesi için beş temel ilke belirtilmiştir (Akın, 2001).

1.Teknolojinin işletme için rekabeti sağlayan önemli bir unsur olarak görülmesi gerekmektedir.

2.Teknolojik olarak gerçekleşebilecek potansiyelin iyi tahmin edilmesi gerekmektedir.

3. Planlı olarak yapılan teknoloji stratejileri doğrultusunda teknoloji tahminleri yapılmalıdır.

4.Yeni teknolojilerle üretilen yeni ürünler piyasaların isteklerine ve ihtiyaçlarına göre özenle pazarlanmalıdir.

5. İşletmenin stratejisi ve teknoloji birbirinden ayrılmaz bir bütün olarak değerlerlendirilmelidir.

\section{SONUÇ}

Bilginin işletmeye yenilik getiren ve işletmeyi rekabetçi yapan özelliklerinden yararlanabilmek için işletmeye katma değer katan ve stratejik bir araç olarak kullanılması gereklidir. Geçmişten bugüne kadar elde edilen her çeşit bilgi teknolojik gelişmeler için kaynak sağlamış ve günümüzde işletmelere rekabet üstünlüğü sağlayan çok önemli bir örgütsel kaynak halini almıştır. Bir yandan da işletmelerin günümüzdeki zorlu rekabet ortamında ayakta kalabilmesi ve aynı zamanda rekabette üstünlük sağlayabilmesi için teknoloji oldukça önemli yere sahiptir ki bu da bilgi yönetimiyle sağlanmaktadır.

Günümüzde artık başarılı firma yöneticileri sermaye ve fiziksel varlıkları artırmaktan çok bilgi ve bilgi yönetimi konularına önem vererek insan üzerine yatırımlara odaklanmaktadırlar. Sürdürülebilir bir rekabet üstünlüğü sağlayabilmenin doğrudan yenilikçilik ve öğrenme yetenekleri ile ilgili olduğu konusu zamanla farkındalığa sebep olmuştur.

Sonuç olarak bilgi yönetimini başarılı bir şekilde uygulayabilen şirketler rekabet ortamında diğer şirketlere göre değişimlere uyum sağlayabilecek ve içinde bulunduğumuz küresel rekabet ortamında rakiplerinden daha fazla avantajsağlayarak bir adım öne geçecektir.

\section{KAYNAKÇA}

Abdullah, R., Selamat, M., Sahibudin, S., \& Alias, R. (2005). A framework for knowledge management system implementation in collaborative environment for higher learning institution. Journal of Knowledge Management Practice.

Akdeniz, T. (2002). Bilgi yönetimi. www.google.com.tr

Akın, H. B. (2001). Yeni ekonomi : strateji, rekabet, teknoloji yönetimi. Ç̧zgi Kitabevi.

Awad, E. M., \& Ghaziri, H. M. (2010). Knowledge management. International Technology Group Ltd.

Barca, M. (2002). Yeni ekonomide bilgi yönetiminin stratejik önemi. I. Ulusal Kongresi, Ekonomi ve 
Yönetim, 517-527.

Barutçugil, İ. (2002). Bilgi Yönetimi. Kariyer Yayınları.

Buckman, R. H. (2004). Building a knowledge-driven organization. McGraw-Hill.

Canbazoğlu, T. (2000). Yararlı Bilgi Yönetiminde İnsan Faktörü. Türkiye Bilişim Vakfı Eğitim Seminerleri:17.

Çapar, B. (2003). Bilgi Yönetimi: Nasıl Bir İnsan Gücü? II. Ulusal Bilgi, Ekonomi ve Yönetim Kongresi, 421432.

Carneiro, A. (2000). How does knowledge management influence innovation and competitiveness? Journal of Knowledge Management, 4(2), 87-98.

Certo, S. C. (1989). Principles of modern management : functions and systems. Allyn and Bacon.

Davenport, T. H., \& Prusak, L. (2001). İş Dünyasında Bilgi Yönetimi. Rota Yayın Yapım Tanıtım Tic. Ltd. Şti.

Earl, M. J. (1991). Information management: the strategic dimension (Oxford Ins). Clarendon Press.

Güçlü, N., \& Sotirofski, K. (2006). Bilgi Yönetimi. Türk Eğitim Bilimleri Dergisi, 4(4), 351-373.

Harrison, R., \& Kessels, J. (2003). Human resource development in a knowledge economy: an organisational view. Palgrave Macmillan.

Kalkan et al. (2006). Örgütsel Öğrenme ve Bilgi Yönetim. Elektronik Sosyal Bilimler Dergisi, 5(16), 22-36.

Koçel, T. (2003). İ̧sletme Yöneticiliği (9. Baskı). Beta Yayınları.

Malhotra, N. (2003). The Nature of Knowledge and the Entry Mode Decision. Organization Studies, 24(6), 935-959.

Nonaka, I. (1999). The Knowledge Creating Compnay. Harvard Business Review On Knowledge Management, Harvard Business School Press, U.S.A.

Öğüt, A. (2001). Bilgi Çağında Yönetim. Nobel Yayınları.

Özgener, Ş. (2002). Global Ölçekte Değer Yaratan Bilgi Yönetimi Stratejileri. 1. Ulusal Bilgi Ekonomisi ve Yönetim Kongresi Bildirileri, 483-496.

Sarıhan, H. (1998). Teknoloji Yönetimi. Desnet Yayınları.

Şimşek, M., \& Akın, B. (2003). Teknoloji Yönetimi ve Örgütsel Degişim. Çizgi Kitapevi.

Sümer, B. (2003). Yerli bilgi. http://www.ceterisparibus.net/arsiv/b_sumer2.doc.yenilik.htm

Uzun, H., \& Durna, U. (2008). İşletmelerde Rekabet Unsuru Olarak Bilgi Yönetimi. Niğde Üniversitesi İktisadi ve İdari Bilimler Fakültesi Dergisi, 1(1), 33-40.

Zaim, H. (2005). Bilginin Artan Önemi ve Bilgi Yönetimi. İşaret Yayınları. 